\title{
Significados de felicidad en narrativas de ciudadanos de Manizales, Caldas
}

Meanings of happiness in narratives of citizens from Manizales, Caldas

RESUMEN

El presente trabajo busca comprender los significados de felicidad presentes en narrativas de ciudadanos de Manizales, departamento de Caldas. El método se fundó en el enfoque histórico hermenéutico para aplicar la entrevista de grupo focal que se hizo en el 2018, como técnica de recolección de información, llevando a cabo la comprensión de los significados de felicidad. Como resultado afloraron seis horizontes interpretativos aparte de los significados de felicidad en el contexto político, económico, social, espiritual y ambiental. Se concluye que los ciudadanos conciben la felicidad entre la disyuntiva de las imposiciones del capitalismo en torno al consumismo y la acumulación de bienes materiales, además bajo la conciencia de una vida en sociedad mediada por un vínculo de interdependencia relativo al sentimiento empático-compasivo.

Palabras clave: felicidad, significados, capitalismo, sentimiento empático-compasivo.
Juan Manuel Vélez-Arias

Magíster en Desarrollo Sostenible y Medio Ambiente, Universidad de Manizales.

$\square$ juanmanuelvelezar@gmail.com (1) ORCID: 0000-0003-3696-2159 जิ Google Scholar 


\begin{abstract}
This work seeks to understand the meanings of happiness in the narratives of citizens of Manizales, Department of Caldas. The method was based on the historical hermeneutic approach to apply the focus group interview performed in 2018 as an information gathering technique, carrying out the understanding of the meanings of happiness. As a result, six interpretive horizons emerged in addition to the meanings of happiness in the political, economic, social, spiritual and environmental context. It is concluded that citizens conceive happiness between the dilemma of the impositions of capitalism on consumerism and the accumulation of material goods, also under the awareness of a life in society mediated by a bond of interdependence relative to the empathic-compassionate feeling.
\end{abstract}

Key words: happiness, meanings, capitalism, empathic-compassionate feeling.

\title{
Introducción
}

a felicidad es un asunto del cual se vienen ocupando diferentes gobiernos, instituciones y áreas del conocimiento en aras de dilucidar su comportamiento individual y social. Según Mill (2014): "por felicidad se entiende el placer y la ausencia de dolor, por infelicidad el dolor y la ausencia de placer" (p. 60). La característica principal de este estado emocional obedece al hecho de ser un aspecto vivencial que cada persona quiere experimentar, del cual desea gozar, sentir o alcanzar, sin importar el lugar o el tiempo; es una aspiración presente en la mayoría de las culturas.

En el utilitarismo de John Stuart Mill la felicidad está dada por la experimentación y selección de placeres dotados de cualidades especiales; es decir, de placeres superiores que obedecen a la virtud del hombre, quien debe estar regido moralmente por el principio de utilidad, el cual versa sobre un criterio de conducta que propende por la felicidad del mayor número de personas (Mill, 2014). En ese sentido, Mill transita reiterativamente sobre la necesidad de hilar la felicidad del individuo con la existencia de ésta en los demás, en el mayor número de personas posibles, por tanto, actualmente tal desiderata se asemeja al influyente proceder del altruismo practicado especialmente por culturas orientales y que según Ricard (2016), nace como un sentimiento de empatía que luego hace 
posible la compasión, resultando todo ello en felicidad para los demás y para uno mismo.

Con la finalidad de conocer más a fondo lo que implica para las personas la felicidad es importante mencionar sus características. Una de ellas es la importancia que le da el ser humano a su condición existencial; en ese sentido, el individuo desea llevar una vida plena donde cada una de las experiencias debe estar dotadas de elementos positivos constitutivos de un bienestar.

El libro Felicidad: lecciones de una nueva ciencia, de Richard Layard 2008, da cuenta de la necesidad de que los Estados asuman la felicidad como un asunto importante; para ello, deben trabajar sobre políticas públicas basadas en este concepto. Uno de los aportes más significativos de sus estudios, realizados en Europa y EE. UU., es su consideración acerca que el individualismo y la priorización de la riqueza en las sociedades occidentales fallaron en la búsqueda de la felicidad. Adicionalmente, la renta produce felicidad cuando saca a las personas de la pobreza extrema; sin embargo, el aumento sin precedentes en los ingresos de los últimos años lo que ha causado es mayor infelicidad (Tula, 2015). En ese orden de ideas, la paradoja de Easterlin lo confirma: "El hallazgo de Easterlin también mostraba que en el manejo de panel de la información, la relación entre ingreso y felicidad no era significativamente diferente de $\mathrm{O}$, lo que indica que la felicidad no es afectada por el crecimiento económico" (Rojas, 2009, p. 551).

La investigación de la felicidad en Manizales se realizó por el interés de conocer la forma en que los ciudadanos buscan ser felices en un contexto sociopolítico determinado por el capitalismo; en el cual la sociedad de consumo establece imaginarios colectivos por los cuales las personas se ven obligadas a concebir o buscar la felicidad fundada en el consumismo y la acumulación de bienes materiales, sin tener conciencia de lo que estos ideales implican para el deterioro del medio ambiente, sus relaciones interpersonales y, concretamente, en la posibilidad de alcanzar una verdadera felicidad.

En ese orden de ideas, resulta importante comprender lo que significa para los manizaleños la felicidad en un contexto como el mencionado y establecer las concepciones del fenómeno estudiado en los campos político, económico, social, espiritual y ambiental. De modo tal que, la filosofía hermenéutica de Hans Georg Gadamer representa el soporte teórico y la herramienta metodológica que le aporta a esta investigación elementos útiles en la consecución de su objetivo: comprender los significados de 
felicidad presentes en narrativas de ciudadanos de Manizales, Caldas, en el año 2018.

Realizar este estudio representa un interés académico en la medida en que las ciencias sociales y humanas permiten abordar problemáticas, realidades y desafíos de la conducta humana en sociedad. En el ámbito del desarrollo sostenible, la línea de investigación Desarrollo Social y Humano de la Universidad de Manizales, busca estudiar alternativas dirigidas a la construcción de nuevas formas sociales y humanas en aras de resultados investigativos que aporten elementos epistemológicos al desafío de la sostenibilidad.

En el marco del enfoque histórico hermenéutico este trabajo tuvo un despliegue metodológico que inicia con la aplicación de una entrevista de grupo focal como técnica de recolección de información, en la que participó un ciudadano representativo de cada una de estos contextos: político, económico, social, espiritual y ambiental. Una vez elaborada la apertura de la entrevista grupal se realiza una pregunta por cada objetivo específico; allí fluyó un diálogo espontáneo en el que los participantes entretejieron los significados de felicidad y respondieron a los objetivos del trabajo investigativo.

\section{Referente teórico}

\section{Cómo definen algunos autores la felicidad}

Jean-Paul Margot

(...) si el hombre quiere ser feliz, no debe olvidar que la felicidad es el resultado de una conquista primero sobre él mismo y luego sobre un mundo en el que debe tener en cuenta no solamente las fuerzas naturales, sino también a los demás hombres. (Margot, 2007, p. 55)

Aristóteles

(...) La felicidad es el bien supremo deseable por sí y nunca por otra cosa, porque es final y autosuficiente dado que "es el fin de todo lo que hacemos". La felicidad es lo más bello y placentero "es una forma de actividad del alma conforme a la virtud, mientras algunos de los demás bienes están incluidos necesariamente en la felicidad, al paso que otros más, son por su naturaleza auxiliares y útiles en forma instrumental" (Aristóteles, 1094a-2010, citado por Baquero, 2016, p. 83) 


\section{Descartes}

La felicidad [béatitude] consiste en un perfecto contento de espíritu y en una satisfacción interior [un parfait contentement d'esprit et une satisfaction intérieure] que no suelen poseer los más favorecidos por la fortuna, y que los sabios adquieren sin ella. Así, [vivere beate], vivir con felicidad [béatitude], no es otra cosa que tener el espíritu perfectamente contento y satisfecho [l'esprit parfaitement content et satisfait]. (Adam, C. Tannery, P. 1897-1909, citado por Margot, 2007, pp. 65-66)

\section{Chamalú}

La felicidad es la chispa de la vida, es suficiente para desentumecer el alma educada de esta civilización; más que un estado de ánimo, es un estado del ser, una frecuencia vibratoria que no es ni debería ser influida desde afuera. Felicidad es esa energía que hace crujir cada momento, revistiendo de luz la existencia; es la contemplación total de la vida, es ignorar a la infelicidad y sumergirse en vivir el instante y desde él adherirse a la eternidad, reservada para quienes profundizan. (Espinoza, 2015, p. 16)

\section{Sonja Lyubomirsky}

Defino la felicidad en dos componentes: la experiencia de emociones positivas frecuentes (alegría, el orgullo, entusiasmo, y la tranquilidad); y el sentido de que estás logrando tus metas en la vida y que estás satisfecho con la forma que está tomando. (Lyubomirsky, 2012, p. 105)

\section{Lofti El-Ghandouri}

La felicidad es la audacia de provocar en la oscuridad un rayo de luz, de transformar un instante ordinario en un momento mágico. (El-Ghandouri, 2012, p. 119)

\section{El utilitarismo de John Stuart Mill}

John Stuart Mill resalta la trayectoria de múltiples posturas de la filosofía moral en cuanto a la diferenciación de lo que es considerado correcto e incorrecto de la conducta humana. Sin embargo, ante la ausencia de un criterio evidente que determine y valore lo correcto o incorrecto, el ser humano generalmente se vale de respuestas intuitivas, que repercuten negativamente en su ideal de felicidad. En palabras de Mill (2014), "por felicidad se entiende el placer y la ausencia de dolor, por infelicidad el dolor y la ausencia de placer" (p. 60). El utilitarismo de Mill deja ver un aspecto importante en las acciones del ser humano, partiendo de 
que todas estas tienen un fin: "el placer y la exención del sufrimiento son las únicas cosas deseables como fines" (Mill, 2014, p. 60). En consecuencia, para Mill la filtración interna referente a los juicios morales surge desde la razón y no meramente a partir de las facultades sensitivas (Mill, 2014, pp. 51-52).

La búsqueda de la felicidad depende de la realización de actividades motivadas por deseos estructurados, que habitan en el inconsciente después de la absorción mental de externalidades físicas y metafísicas propias del entorno; de ahí la importancia de ser personas cultivadas intelectual y espiritualmente. Es allí donde el placer cobra relevancia, pues la cuestión está en saber seleccionarlo ante su diversidad y conveniencia. Para Mill (2014), la teoría utilitarista tradicional ha puesto por encima los placeres mentales sobre los corporales, empero, es él quién llena un vacío al establecer la deseabilidad de los mismos.

La teoría de Stuart Mill continúa en esa línea de hedonismo universalista de sus antecesores; en su obra resalta las cualidades que adquiere el hombre al enriquecer su intelecto, la nobleza y la consciencia de aportar desinteresadamente a los males de la vida desde su dimensión personal, social y política, con la conciencia de que se debe trabajar desde el individuo, pues es finalmente quien mejorará las condiciones del mundo.

\section{Cualificación de los placeres}

El epicureísmo concibió el placer como uno de sus bienes más preciados. Así lo menciona Epicuro en Carta a Meneceo:

Afirmamos que el placer es el principio y el fin de una vida feliz, porque lo hemos reconocido como un bien primero y congénito, a partir del cual iniciamos cualquier elección o aversión y a él nos referimos al juzgar los bienes según la norma del placer y del dolor. $\mathrm{Y}$, puesto que éste es el bien primero y connatural, por este motivo no elegimos todos los placeres, sino que en ocasiones renunciamos a muchos cuando de ellos se sigue un trastorno aún mayor. (Epicuro, 1994, p. 61)

Aquí, en un pensamiento conciso acerca de la preferencia de placeres, el autor muestra la necesidad del placer para la felicidad y la prevalencia de unos sobre otros; en esta doctrina antigua el placer es fuente de felicidad. Esta misma línea de pensamiento es desarrollada varios siglos después en Inglaterra con Jeremy Bentham en materia legislativa, en efecto: 
Los placeres entonces y la evitación de los dolores, son los fines que el legislador tiene en cuenta; le incumbe, por tanto, comprender su valor. Los placeres y dolores son los instrumentos con que tiene que trabajar; le incumbe, por tanto, entender su fuerza, lo que nuevamente en otras palabras, es su valor. (Bentham, 2008, p. 35)

Bentham dotaría los placeres de valor de acuerdo con:

1. Su intensidad, 2. Su duración, 3. Su certeza o incerteza, 4. Su proximidad o distancia, 5. Su fecundidad, 6. Su pureza y otra más, o sea: 7. Su alcance, es decir, el número de personas a quienes se extiende, en otras palabras, que son afectadas por ella. (Bentham, 2008, p. 36)

En este sentido, es atribuible al utilitarismo el interés por instaurar placeres integrales, puesto que Mill reafirmó teóricamente la importancia de cualificar los mismos. "Es del todo compatible con el principio de utilidad el reconocer el hecho de que algunos tipos de placeres son más deseables y valiosos que otros" (Mill, 2014, pp. 62-63). El autor, en este caso, no sólo continúa con la línea de su maestro, sino que además entra a considerar el valor decisivo entre los placeres confiándole el calificativo de calidad. Así, Mill (2014) reflexiona sobre la posible tensión entre los placeres:

Si se me pregunta qué entiendo por diferencia de calidad en los placeres, o qué hace a un placer más valioso que otro, simplemente en cuanto placer, a no ser que sea su mayor cantidad, sólo existe una única posible respuesta. De entre dos placeres, si hay uno al que todos, o casi todos los que han experimentado ambos, conceden una decidida preferencia, independientemente de todo sentimiento de obligación moral para preferirlo, ese es el placer más deseable. (pp. 63-64)

Ahora, cuando el autor menciona "a no ser que sea su mayor cantidad" cae en el vacío de saber si pueda existir un placer elevado que sea tan poco dotado de valor que exista la posibilidad de ser superado por la experimentación de la sumatoria de otros placeres no tan cualificados. En ese caso, la suma de los placeres estaría por encima de la naturaleza del mismo. Y como cabe la posibilidad de negarse a realizar tal elección por las connotaciones éticas que le pueda suscitar este dilema, podría considerarse que cuando menciona "independientemente de todo sentimiento de obligación moral para preferirlo", el individuo responde a esa naturaleza del placer llevándolo a seleccionar el placer más deseable. 


\section{Funcionalidad de la hermenéutica en la comprensión de la realidad local}

Luego que la hermenéutica se despojara de sus vínculos a la forma más convencional de aprehender los textos, la comprensión se eleva a un plano más aventurado y enriquecedor. La praxis interpretativa cobra un valor de carácter ecuménico. Al respecto, dice Herrera (2010) que:

(...) la interpretación para la filosofía hermenéutica, es la explicitación de esa comprensión básica del mundo en la que siempre estamos. Fue Heidegger, el primero en elevar la comprensión a rasgo fundamental del ser humano; antes de él, la comprensión se entendía como una especie de captación mental del sentido de algo, y la interpretación como la aclaración de un texto cuando este resultaba difícil de entender. (Herrera, 2010. p. 125)

En ese sentido, la comprensión de una realidad se desprende de toda simplificación, en el ocaso del entendimiento reducto y meramente ocasional del ser. Según Gadamer (2004) eso significa reajustar la expectativa y hacer confluir el texto en la unidad de un pensamiento desde otra expectativa de sentido" (p. 63). Por eso, la interpretación requiere de un razonamiento amplio y virtuoso otorgado por la comprensión.

El quehacer de la interpretación -a diferencia del comprenderno reposa en el entendimiento final y completo del texto, ya que ésta, la interpretación, es simplemente un recurso esclarecedor de lo que se pretende con la comprensión; de tal modo que para Gadamer (2003):

La interpretación se ocupa expresamente de "discursos y escritos racionales". Interpretar significa para él "aducir los conceptos que sean necesarios para la comprensión completa de un pasaje". Por lo tanto, la interpretación no debe "indicar la verdadera comprensión de un pasaje", sino que lo suyo es expresamente resolver las oscuridades que impiden al escolar la "comprensión completa de los textos" (...). En la interpretación hay que guiarse por la perspectiva del escolar. (p. 236)

¿Qué puede esperarse entonces del conocimiento hermenéutico en la comprensión de significados de felicidad de los manizaleños?

No es únicamente una cuestión de desnaturalizar el método ortodoxo cuando de hallar la realidad contextual se trata y de la cual se ocupa esta investigación, sino que es también la integralidad de una verdad oculta pero que, aun así, deber ser sustraída de la manera más limpia 
posible. El matiz restrictivo de la comprensión aparece cuando el interés por entender la realidad sobrepasa la conexión del texto con sus tradiciones; también cuando se pretende interpretarlo con el lenguaje propio del investigador. Lo anterior dota a la comprensión de autonomía práctica y funcional que Vergara (2008) plantea de la siguiente manera:

Gadamer concibe por hermenéutica como la pregunta filosófica que concierne a la posibilidad de la comprensión en referencia a lo que acontece en la praxis y no en la empiria subjetivista y/o instrumentalista de la comprensión, es decir, en aquello "que ocurre con nosotros por encima de nuestro querer y hacer". (p. 184)

De ahí que la subjetividad en todo momento teórico que le fue entregada a las ciencias sociales por la ciencia moderna, sea replanteada con una forma práctica de abordar la realidad por parte de la hermenéutica. De modo que dicho comportamiento encuentra aquí relativa condición respecto a su relación con el objeto, reforzando este corolario de Gadamer (2003): “(...) que la comprensión no es nunca un comportamiento subjetivo respecto a un 'objeto' dado, sino que pertenece a la historia efectual, esto es al ser de lo que se comprende" (pp. 13-14).

Además, en Gadamer "la hermenéutica es esencialmente una forma de comprensión que "pregunta cómo es posible la comprensión" (Vergara, 2008, p. 184). Y para Gadamer (2003): "Es una pregunta que en realidad precede a todo comportamiento comprensivo de la subjetividad, incluso al metodológico de las ciencias comprensivas, a sus normas y a sus reglas" (p. 12). Así las cosas, Gadamer (2003) siguiendo a Kant, expresa:

La estética del genio ha desarrollado en esto un importante trabajo previo, ya que de ella se desprende que la experiencia de la obra supera por principio siempre cualquier horizonte subjetivo de interpretación, tanto el del artista como el de su receptor. La mens auctoris no es baremo viable para el significado de una obra de arte. Más aún, incluso el hablar de la obra en sí, con independencia de la realidad siempre renovada de sus nuevas experiencias, tiene algo de abstracto. (Gadamer, 2003, p. 13)

\section{Metodología}

En esta investigación se aplicó el enfoque histórico hermenéutico con el fin de interpretar y comprender los significados de felicidad, de acuerdo con el proceso libre y espontáneo de la entrevista de grupo focal 
como técnica de recolección de información. Por tanto, la labor comunicativa fue aprovechada como mecanismo de interpretación, de tal modo que hiciera posible comprender la realidad acerca del tema de investigación.

La interpretación del texto, resultado de las narrativas, permitió realizar la extracción de la realidad oculta donde finalmente se dota de sentido los significados de felicidad de los ciudadanos consultados. Esto es importante para el investigador en materia metodológica, no obstante, es la comprensión del texto acabado la que determina la completitud de la experiencia hermenéutica. La conexión contextual de los ciudadanos entrevistados configura un aspecto fundamental al no concebirlos como sujetos aislados; por el contrario, son ellos quienes tejen un sentido cultural y social-humano a partir de las intersubjetividades imbricadas.

Así, para comprender los significados de felicidad en el contexto social, cultural e histórico gracias al lenguaje desde una perspectiva gadameriana fue clave en este trabajo el principio de historia efectual como componente esencial del círculo hermenéutico. Los pasos del método que siguió esta investigación fueron:

Técnica de recolección de la información: entrevista de grupo focal.

Composición del grupo focal: el grupo focal estuvo compuesto por cinco ciudadanos de Manizales, cada uno de ellos representante de los ámbitos social, político, económico, espiritual y ambiental.

\begin{tabular}{ccccccc}
\hline Ámbito & Género & $\begin{array}{c}\text { Rango de } \\
\text { edad }\end{array}$ & $\begin{array}{c}\text { Estado } \\
\text { civil }\end{array}$ & $\begin{array}{c}\text { Posición en el } \\
\text { hogar }\end{array}$ & $\begin{array}{c}\text { Profesión u } \\
\text { ocupación }\end{array}$ & $\begin{array}{c}\text { Estrato } \\
\text { socioeconómico }\end{array}$ \\
\hline Político & $\mathrm{M}$ & $55-60$ & Casado & Padre & $\begin{array}{c}\text { Arquitecto, } \\
\text { profesor y } \\
\text { político. }\end{array}$ & 4 \\
\hline Económico & $\mathrm{F}$ & $60-65$ & Casada & Madre & $\begin{array}{c}\text { Economista, } \\
\text { gerente de } \\
\text { entidad bancaria. }\end{array}$ & 6 \\
\hline Social & $\mathrm{M}$ & $60-65$ & $\begin{array}{c}\text { Unión } \\
\text { libre }\end{array}$ & Padre & $\begin{array}{c}\text { Docente, } \\
\text { investigador, } \\
\text { psicólogo. }\end{array}$ & 4 \\
\hline Espiritual & $\mathrm{M}$ & $40-45$ & Soltero & Sacerdote & Sacerdote & 4 \\
\hline \multirow{2}{*}{ Ambiental } & $\mathrm{F}$ & $60-65$ & Casada & Madre & $\begin{array}{c}\text { Ambientalista, } \\
\text { activista, } \\
\text { docente. }\end{array}$ & 3 \\
\hline
\end{tabular}

Fuente: Elaboración propia. 
Unidad de análisis: significados de felicidad.

Población objeto: La investigación se dirige a la sociedad de Manizales representada por un participante de cada ámbito destacado; es decir, un representante por cada ámbito social, económico, político, espiritual y ambiental. Se determinó la participación de estas personas considerando la diversidad de sus roles en la sociedad, reconociendo que, aunque sean partícipes en escenarios diferentes, cada uno de ellos enmarca labores importantes para la sociedad en general; es decir que estos representantes se han destacado en cada uno de sus ámbitos, conocen a fondo el contexto en que se desenvuelven y han adquirido la suficiente experiencia, objetividad y responsabilidad a la hora de comunicar sus pensamientos. Las edades pueden corresponder a las frecuentemente alcanzadas para llegar a representar la sociedad desde cada una de sus perspectivas.

La selección de los participantes se llevó a cabo rigurosamente, haciendo un filtro de perfiles y condiciones cognitivas y cognoscitivas de acuerdo con su historial en la sociedad.

\section{Formato de entrevista para realización de grupo focal (preguntas grupo focal)}

La investigación que se está llevando a cabo sobre los significados de felicidad en Manizales nos lleva a realizarles las siguientes preguntas, teniendo la posibilidad de complementar respuestas anteriores y debatir alrededor de las mismas.

Durante los últimos años diferentes gobiernos, sectores académicos y grupos de interés están debatiendo la importancia de la felicidad como alternativa al modelo de desarrollo económico, donde es medido el PIB como mecanismo de cuantificación del progreso. De acuerdo con esta afirmación, es importante para la presente investigación conocer los significados de felicidad que a ustedes les suscitan. En ese sentido: 1) ¿qué es para usted la felicidad?; y 2) ¿qué es para usted la felicidad en el contexto político, económico, social, espiritual y ambiental?

\section{Metodología de la comprensión de significados de felicidad}

En la siguiente tabla se observa el procedimiento aplicado en la comprensión de la realidad. 
Tabla 1. Formato para el análisis interpretativo y comprensivo de los significados de felicidad.

\begin{tabular}{lllll}
\hline Objetivo Técnica & Pregunta & Respuesta & Interpretación & Comprensión \\
\hline
\end{tabular}

Fuente: Elaboración propia.

\section{Resultados}

Una vez aplicada la técnica de recolección de la información, y aprehendido el recurso teórico sobre la hermenéutica, se obtienen 16 significados de felicidad, los cuales se clasifican en seis horizontes interpretativos procedentes del ejercicio exegético aplicado al material obtenido. Lo anterior obedece al primer objetivo investigativo; sin embargo, es con la comprensión de los significados de felicidad enmarcados en sus respectivos horizontes que se da cumplimiento al objetivo general de la investigación.

Objetivo 1: Interpretar los significados de felicidad de ciudadanos de Manizales a partir de sus narrativas.

Técnica aplicada: entrevista de grupo focal realizada con 5 participantes.

Pregunta: ¿Qué significa para ustedes la felicidad?

Horizonte interpretativo: significado de felicidad relativo al consumo o a la acumulación de bienes materiales.

\section{Número de respuestas clasificadas en el horizonte interpretativo: 4}

» Comprensión 1: poder disponer de recursos en abundancia para satisfacer los deseos. Es poder realizar, por ejemplo, compras en centros comerciales y sentirse muy bien con ello.

» Comprensión 2: felicidad es llevar una vida de sencillez compuesta por estadosres del ser humano, una vez allí es posible la sabiduría, serenidad y paz; todos ellos representaciones de lo que logra la persona cuando ama a través de bellas relaciones con el otro. 
Horizonte interpretativo: significado de felicidad relativo al sentimiento empático compasivo.

Número de respuestas clasificadas en el horizonte interpretativo: 2

» Comprensión: felicidad es sentir como el otro, pensar como el otro y preocuparse por las desgracias del otro, es establecer un vínculo emocional traducido en las buenas relaciones interpersonales y la dignificación de cada persona como parte de una sociedad.

Horizonte interpretativo: significado de felicidad relativo a la satisfacción.

Número de respuestas clasificadas en el horizonte interpretativo: 3

» Comprensión: la felicidad es el placer que otorga el cumplimiento de nuestras aspiraciones individuales y colectivas, de modo que el buen resultado de nuestras acciones vaya edificando una satisfacción continua y duradera.

Horizonte interpretativo: significado de felicidad relativo a la subjetividad.

Número de respuestas clasificadas en el horizonte interpretativo: 2

» Comprensión: la felicidad no es un asunto fácil de alcanzar ni de definir, es una construcción constante que, aunque implica condiciones subjetivas, existen configuraciones externas determinantes en el significado de felicidad de cada persona.

Horizonte interpretativo: significado de felicidad relativo al entorno laboral.

Número de respuestas clasificadas en el horizonte interpretativo: 2

» Comprensión: la felicidad para el manizaleño en el entorno laboral es sentirse a gusto con lo que hace, de ello se desprende la capacidad de tener sentido de pertenencia, y cumplir bien con sus labores. De ahí que pueda disfrutar de un reconocimiento de su persona más que de su labor.

Horizonte interpretativo: significado de felicidad relativo a la vida. 


\section{Número de respuestas clasificadas en el horizonte interpretativo: 3}

» Comprensión: es estar precisamente vivo, libre de los límites mentales aducidos por la frialdad de cualquier circunstancia negativa. Es circulación energética y cósmica dentro de los sistemas del cuerpo y los paisajes de la mente. Es reconocer la vitalidad del espíritu en sincronía con un fervor hacía él sin perjuicio de la edad, es el agradecimiento por la existencia vital, el que proporciona bienestar en simultaneidad con la cercanía a los demás y al espíritu superior.

De acuerdo al segundo objetivo de investigación, se realiza la interpretación de los significados de felicidad en los contextos político, económico, social, espiritual y ambiental; de este ejercicio resultan ciertas características para algunos de los contextos, como en el caso del contexto social y económico. Lo anterior unido al proceso objetivo de comprender las interpretaciones de los significados de felicidad obtenidos con la aplicación de la técnica investigativa, dan cumplimiento al objetivo general de investigación.

Objetivo 2: Interpretar el significado de felicidad de ciudadanos de Manizales de acuerdo al contexto: político, económico, social, espiritual y ambiental; a partir de sus narrativas.

Técnica aplicada: entrevista de grupo focal realizada con 5 participantes.

1. Pregunta: ¿Qué es para usted la felicidad en el contexto político?

» Interpretación: "La felicidad en el contexto político es prestar servicios y conocimientos a la sociedad en términos generales, tomando decisiones favorables; es compromiso social, ayudar a los pobres y a las causas colectivas desprendiéndose de lo material y lo personal. Lo cual se concreta con la reivindicación de los derechos sociales y colectivos". (SFRCP) ${ }^{1}$

Comprensión: Es la capacidad del ser humano para renunciar a sus propios intereses, cuando de ayudar a la consecución de mayor felicidad posible comprenda su ideal en acción frente a las circunstancias adversas en las que ha caído la sociedad. 
2. Pregunta: ¿Qué es para usted la felicidad en el contexto económico?

Interpretación: "Es la labor desempeñada por la empresa desde el amor, donde se busca la integralidad del trabajador; teniendo mayor bienestar éste produce más. Es también un estadio donde la empresa establece cercanía sin exclusión con el ciudadano logrando motivación y un vínculo emocionalmente positivo" (SFRCEC) ${ }^{2}$

Comprensión: significado de carácter empresarial. Es la labor que vienen desempeñando las empresas como oportunidad para tener trabajadores en óptimas condiciones de producción y cercanía al cliente, a través del vínculo establecido por emociones positivas.

Interpretación: "Es tener en cuenta el altruismo sin ser la única opción, es también, emprender y lograr contribuir; lo cual dignifica mientras se aporta a la familia y a la sociedad. Es no desnaturalizar la función del dinero, en cambio sí, darle mayor importancia al aspecto humano" (SFRCE) ${ }^{3}$

Comprensión: significado de carácter ontológico. Es el hecho de poder disponer conscientemente del dinero en aras de atender integralmente a la familia y las necesidades laborales del individuo en sociedad, simultáneamente a la dignificación del mismo sin perjuicio de las banalidades en las que pueda incurrir con el poder del mencionado recurso monetario.

\section{Pregunta: ¿Qué es para usted la felicidad en el contexto social?}

Interpretación: "La felicidad es una relación circular; representándose en el otro y desplegándose a la otredad fundamentalmente por una relación vinculante. Es un ejercicio de reconocimiento del otro, que, una vez dado permite la interacción con muestras de respeto, cuidado y buenas relaciones" (SFRCS) ${ }^{4}$

Comprensión: significado de carácter empático-compasivo en el plano individual. La felicidad social es la relación circular de reciprocidad establecida por el vínculo espontáneamente establecido entre el individuo y sus conciudadanos, fundada en las buenas 
relaciones y el interés por el bienestar del otro, que además entretejen la felicidad colectiva.

Interpretación: "Es equidad, inclusión, estabilidad y bienestar; es una empatía generalizada que conduce a la compasión por los males sociales" (SFRCS).

Comprensión: significado de carácter empático-compasivo en el plano colectivo. Es velar por el fortalecimiento de una sociedad incluyente, capaz no solamente de ver en las vicisitudes más nefastas de colectividades vulnerables un sentimiento generalizado de profundo sufrimiento, sino también, una motivación para proporcionar mejores condiciones de vida para la sociedad.

Interpretación: "Es reconocer condiciones establecidas por el modelo económico capitalista, el cual crea necesidades de consumo; en la concienciación sobre necesidades creadas respecto a necesidades reales yace felicidad; mientras que las necesidades creadas son un atenuante de ésta" (SFRCS)

Comprensión: significado de carácter político; es la capacidad racional y práctica del ciudadano para afrontar las imposiciones relativas al consumo y la resolución de necesidades reales y creadas, a partir de la concienciación de aquellas que obedecen a la naturaleza de las dinámicas existenciales en el contexto aprehendido en tensión con las creadas por una sociedad de consumo.

Interpretación: "Es la inclinación y capacidad de disfrutar del ser humano, es decir del prójimo y de situaciones generadores de emociones positivas. Condiciones dadas por el contexto físico espacial del trópico latinoamericano" (SFRCS)

Comprensión: significado de carácter cultural; es el producto de las características topográficas, climáticas y, en general ambientales, en relación con la habitabilidad, complementariedad, interacción y simbolismo del ser humano, quien, por hacer parte de estas condiciones, se comporta sustancialmente gregario, amante del disfrute en sociedad y constantemente proclive a tanta diversión como le sea posible. 
4. Pregunta: ¿Qué es para usted la felicidad en el contexto espiritual?

Interpretación: "Felicidad en el plano espiritual es la capacidad de desprendimiento incluso de la misma vida, es una vida en la sencillez, donde se logra plenitud y realización. Una vez allí, se comparte en familia y en compañía del propio espíritu cultivado por el amor de Dios, el cual despierta diferentes sensaciones" (SFRCE)

Comprensión: es desprenderse de toda atadura material y mental, bajo los designios de Dios, proyectar el amor que nos es transmitido bajo la presencia de sus fuerzas delegadas y el cultivo del espíritu en extensión a los demás y proyectado al reino de los cielos.

5. Pregunta: ¿Qué es para usted la felicidad en el contexto ambiental?

» Interpretación: "Es el vínculo de reciprocidad establecido con el entorno natural, es enamorarse de la naturaleza con todos los seres vivos que la componen. Esta relación armoniosa parte de la capacidad de maravillarse con la existencia de grandes y pequeños seres" (SFRCA)

Comprensión: es el amor que entrega el ser humano a todo ser viviente incluido el entorno natural en que habitan la totalidad de las especies, manifestándose en el cuidado presente y futuro de su supervivencia y bienestar.

\section{Discusión}

Es importante reconocer el papel fundamental de las narrativas de los ciudadanos de Manizales, pues, fueron de gran valor para la construcción de sentido de sus significados y fue a través del diálogo que pudo surgir ese lenguaje necesario para la comprensión de los significados. Es por tal motivo que la selección de los contextos sobre los que se pretendió extraer la realidad referente a los significados de felicidad, fue acertada para el resultado en general; sin estos elementos conceptuales el surgimiento de los diferentes horizontes hermenéuticos pudo haber sido imposible o confuso.

Ahora bien, con base en lo anterior, se discute que los ciudadanos de Manizales comunican dentro de los seis horizontes interpretativos dos significados de felicidad relativos al consumismo o a la acumulación de bienes materiales. En efecto, se evidencia una incuestionable inclinación 
de algunos ciudadanos a responder a las premisas del capitalismo, donde la sociedad de consumo impone condiciones como el individualismo, la adulación del dinero y la satisfacción de placeres superfluos que, en definitiva, no aportan a la felicidad individual y colectiva. Lo anterior es sustentable con los siguientes aportes teóricos:

Un sistema económico no solo produce bienes y servicios. También produce seres humanos y relaciones entre estos. La forma en que la sociedad produce y consume influye mucho en las personalidades, caracteres, conocimientos, deseos, felicidades y tipos de relaciones interpersonales. (Ricard, 2016, p. 581)

El significado otorgado aquí a la felicidad desde el condicionamiento de un modelo económico no es una simple idea, sino que además tiene sus justificaciones teóricas y prácticas desde el acontecer de las formas sociales. Una forma de comprender esto, la proporciona Mill (2014):

Pero no creo que quienes merecen esta acusación tan común escojan voluntariamente los placeres inferiores con preferencia a los superiores. Creo que antes de dedicarse exclusivamente a los unos, se han incapacitado ya para los otros. La capacidad para los sentimientos más nobles es en muchas naturalezas una planta muy tierna que muere con facilidad, no sólo por influencias hostiles, sino por la mera falta de alimentos. En la mayoría de las personas jóvenes muere prontamente, si las ocupaciones a las que les lleva su posición, o el medio social en que se encuentran no son favorables al ejercicio de sus facultades. Los hombres pierden sus aspiraciones elevadas como pierden su agudeza intelectual, porque no tienen tiempo ni oportunidad para favorecerlas. Se adhieren a los placeres inferiores, no porque los prefieran deliberadamente, sino porque son los únicos a que tienen acceso, a los únicos de que pueden gozar duraderamente. (Mill, 2014, p. 144)

La priorización de los placeres que Mill contempla, se relaciona en la actualidad con las personalidades, preferencias o prácticas adoptadas por el ciudadano de a pie, y que consecuentemente implican condiciones de satisfacción frente a la vida de acuerdo con su modus vivendi, como lo demuestra el siguiente argumento de Ricard (2016):

Tim Kasser, autor de The High Price of Materialism ('El alto precio del materialismo') y sus colegas (...) establecieron que los individuos más inclinados al consumo de todo tipo de bienes y servicios los que priorizan la riqueza, la imagen, el estatus social y otros valores 
materiales promovidos por una sociedad llamada de consumo se sienten claramente menos satisfechos con su vida que aquellos que ponen el acento en los valores más fundamentales de la existencia como la amistad, la satisfacción, la calidad de la experiencia vivida, la preocupación por los demás, así como el sentimiento de responsabilidad con respecto a la sociedad y al medio ambiente. (Ricard, 2016, p. 617)

La anterior es una discusión formulada al primer significado de felicidad relativo al consumismo o a la acumulación de bienes materiales; no obstante, algunos manizaleños expresan un significado totalmente opuesto al primer resultado, aunque relativo al mismo horizonte interpretativo. Al respecto, Mill (2014) propone una distinción entre los placeres más deseables en una vida cercana a la felicidad del mayor número de personas posibles:

Si se me pregunta qué entiendo por diferencia de calidad en los placeres, o qué hace a un placer más valioso que otro, simplemente en cuanto placer, a no ser que sea su mayor cantidad, sólo existe una única posible respuesta. De entre dos placeres, si hay uno al que todos, o casi todos los que han experimentado ambos, conceden una decidida preferencia, independientemente de todo sentimiento de obligación moral para preferirlo, ése es el placer más deseable. (Mill, 2014, pp. 63-64)

En tanto que para Gandhi, "La civilización, en el verdadero sentido de la palabra, no consiste en multiplicar los deseos sino en reducirlos voluntariamente. Sólo esto establece la verdadera felicidad y la satisfacción, aumentando nuestra capacidad de servir" (Ricard, 2016, p. 615).

Con la finalidad de comprender una realidad desde la postura gadameriana, la hermenéutica sugiere fundamentalmente la tradición o historia que le pertenece al objeto como condición para comprenderlo de manera objetiva. Por tanto, como primera medida, es necesario reconocer aquí una tensión entre estos significados de felicidad, factores correspondientes a la historia efectual de este fenómeno social-humano y, por ende, cultural.

Por su parte, Londoño (1936), en su labor historiográfica acerca de Manizales describe características de los manizaleños, durante la primera mitad del siglo $\mathrm{XX}^{5}$. 
Si el espíritu de asociación no se ha implantado o desarrollado en Manizales para empresas industriales o para la explotación de tanta industria que hubiera adelantado la riqueza colectiva, al par que la individual, sí ha existido y pudiera considerarse como una obsesión, el deseo de los manizaleños para asociarse con fines meramente caritativos y filantrópicos. (Londoño, 1936, p. 114)

Lo que puede concluirse al respecto de estos dos significados de felicidad, es que cuando han estado de por medio los intereses económicos, la posibilidad de asociación o la ilación de los intereses no ha sido una constante o un asunto característico de los manizaleños. Al respecto:

Para Godelier, las sociedades capitalistas actuales presentan condiciones sociales sumamente diferentes a aquéllas que daban argumento y sentido a la tesis sobre el "don" planteados por Marcel Mauss. Actualmente vivimos en sociedades donde el tejido social se ha desmembrado y donde el fenómeno de exclusión social ha adquirido dimensiones alarmantes. Para este autor, la existencia social de los individuos depende de la economía, de modo que cuando un sujeto pierde su empleo, en realidad está perdiendo mucho más que eso. (Enríquez, 2000, p. 40)

El interés por las personas necesitadas y el deseo de ayudar a los demás, históricamente sí ha presentado un interés genuino de los ciudadanos. Pero, cuando la persona acude a la consciencia, expresa significados de felicidad referentes al sentimiento causado por un capitalismo vigente y fortalecido con las políticas neoliberales presentes en el sistema político y económico, como el de la siguiente narrativa:

Felicidad es disfrutar de las relaciones que tenemos con el ambiente, el diálogo, el arte; allí donde no hay saturación de los productos y el consumismo. Es vivir cada instante sin prisa en lugares indeterminados disfrutando de la independencia hacia los patrones de consumo siendo conscientes de las falsas promesas del capitalismo. Es darle sentido a la vida. $(\mathrm{NPCA})^{6}$

Al interpretar los significados de felicidad de ciudadanos de Manizales se presentó el caso común de encontrar en varias de las respuestas el término: subjetivo; en ese caso las personas manifestaban lo siguiente: 
Todo es una sensación subjetiva también, porque pues ya sabemos que personas por ejemplo que ganan muchísimo dinero, pero deciden suicidarse en la mitad del camino, y, al contrario, personas con extremas necesidades de pobreza que se declaran felices, entonces eso es un factor absolutamente subjetivo. (NPCP) ${ }^{7}$

La felicidad es un asunto paradójico en la medida en que se realizan proyectos que pueden generar felicidad pero que, aun realizándolos, la persona lleva una vida de sufrimiento e infelicidad. (NPCA)

Lo anterior guarda relación con el estudio de pobreza subjetiva realizado por Pinzón (2017), así:

La pobreza subjetiva considera la percepción de los individuos $\mathrm{u}$ hogares sobre su bienestar y cotidianidad, definiéndose como aquella situación en la cual, pese a tenerse ingresos que superan el mínimo de subsistencia, se gana menos de lo que se necesita para no sentirse pobre. En otras palabras, es el grado de insatisfacción con la situación en la que se está, al no tener el nivel de vida deseado. Así, hogares catalogados como pobres objetivos puede que no se autoperciban como pobres, mientras que quienes no son ubicados como pobres puede que sí se consideren pobres al no tener el nivel de vida que desearían tener. (Pinzón, 2017, p. 13)

Por consiguiente, la felicidad no es un asunto fácil de alcanzar ni de definir; es una construcción constante que, aunque implica condiciones subjetivas, existen configuraciones externas determinantes en el significado de felicidad de cada persona (comprensión horizonte interpretativo $\mathrm{N}^{\mathrm{0}} 4$ ).

Margot (2007) lo explica de la siguiente manera:

Decir que nuestra idea de felicidad tiene un elemento subjetivo no implica que cada uno de nosotros invente su ideal de felicidad: este ideal se construye según las formas y los criterios que son suministrados por la cultura y la sociedad: la concepción de la felicidad varía según la época y el tipo de sociedad. (p. 57)

Lo anterior guarda relación con las variables estudiadas por Pinzón (2017), condiciones como la vivienda, alimentación, ingresos, género, edad, educación, etc. Determinan la autopercepción de pobreza subjetiva. 
Dichos componentes hacen parte de condiciones en la vida y servicios propios de la existencia en sociedad, empero no comprenden la totalidad de las formas y criterios socio-culturales estipulados en Margot y diferentes a las condiciones subjetivas del individuo como la consciencia, el amor, la espiritualidad o el placer; lo cual comprendería el ideal de felicidad. En efecto, es Margot (2007) quien soporta la idea de la necesidad de un plano objetivo para la felicidad, como son las formas y criterios socioculturales. Dichas formas y criterios pueden corresponder a la estructura social siendo la manera del individuo de asumir tal condición la que configura en la intersubjetividad aspectos como la satisfacción o insatisfacción, analizados en Pinzón (2017) según su relación con la pobreza subjetiva.

En la categoría, significado de felicidad relativo al sentimiento empático-compasivo, es interpretado el significado de felicidad de acuerdo con el interés que surge en las personas por acudir al prójimo, por pensar en el otro e inquietarse por él. Tal significado obedece al carácter vinculante que la naturaleza humana expresa cuando la persona conforma una sociedad; es decir, la condición de compartir un espacio y tiempo con otros individuos aflora los sentimientos más nobles cuando los intereses individuales no se limitan al bienestar exclusivo de quien los experimenta. Adicionalmente, la condición de empatía no significa un despliegue de acciones en pro de los demás, aunque trascendiendo a una condición compasiva, la felicidad es proclive a darse. El significado antes mencionado es acorde a la teoría del utilitarismo, en congruencia con las siguientes palabras de Mill (2014, p. 69):

la utilidad o felicidad es considerada como regla directriz de la conducta humana. Sin embargo, no constituye en modo alguno una condición indispensable para la aceptación del criterio utilitarista, ya que tal criterio no constituye la mayor felicidad del propio agente, sino de la mayor cantidad total de felicidad. Si puede haber alguna duda de que una persona noble pueda ser más feliz a causa de su nobleza, lo que sí no puede dudarse es que hace más felices a los demás y que el mundo en general gana inmensamente con ello.

El placer elevado o cualificado de servirle a los demás es la fuente de felicidad en la persona noble; felicidad es, entonces, disfrutar del placer desinteresado que proporciona el servicio a los demás. Para complementar la discusión referente al anterior significado, se cita a continuación una interpretación de otro significado de felicidad relativo al sentimiento empático-compasivo extraído de las narrativas: 
Felicidad es la posibilidad de servir, de cuidar y empatizar. Es el placer que dan estos hechos y que corresponden a la subjetividad del ser representándose en un estado de ánimo duradero caracterizado por el bienestar y las emociones positivas que, además, se obtiene por la realización de estos objetivos. (NPCS)

La comprensión en tal caso es dedicada al concepto del cuidado como un comportamiento que busca, además de felicidad, la evitación del sufrimiento o infelicidad sugerido por Mill (2014), quien afirma:

Sin embargo, incluso en tal caso, se podría defender en algún sentido la doctrina utilitarista, ya que la utilidad incluye no sólo la búsqueda de la felicidad, sino la prevención y mitigación de la infelicidad, y si el primer objetivo resultase quimérico, mayor importancia adquiriría el segundo, existiendo una necesidad más imperiosa del mismo en tanto en cuanto la humanidad considerase adecuado el seguir viviendo y no refugiarse en la acción alternativa del suicidio recomendada en circunstancias por Novalis. (p. 71)

El término compasión no merece ser excluido de la anterior comprensión. En ese sentido la alternativa propuesta por el altruismo de Ricard (2016) expresa:

Queda, pues, la compasión, cuya esencia es una motivación altruista, necesaria y suficiente para que deseemos el bien del otro y generemos la voluntad de darle cumplimiento mediante la acción. En efecto, esta compasión es consciente de la situación del otro y está asociada al deseo de aliviar su sufrimiento y procurarle bienestar. Por último, no está lastrada por una confusión entre las emociones sentidas por el otro y las nuestras. (p. 77)

En el altruismo propuesto por Ricard (2016) es una constante tal preceptiva:

Al hablar de las "causas de la felicidad", el budismo no se refiere sólo a las causas inmediatas del bienestar, sino a sus raíces profundas, a saber, la búsqueda de la sabiduría y de una comprensión más justa de la realidad. Este deseo altruista va acompañado de una constante disponibilidad hacia el otro, asociada a la determinación de hacer todo cuanto esté en nuestro poder para ayudar a cada ser en particular a conseguir una auténtica felicidad. (p. 49) 
El significado de felicidad en el contexto económico de carácter empresarial concuerda con los postulados de la psicología positiva, desde esta disciplina se viene trabajando en las empresas para lograr mayor productividad al tener trabajadores felices; Vallejo (2012) muestra que:

La emoción asociada a estas fortalezas, inertes a todo ser humano, resulta de una pujanza que todo lo arrolla y nos permite, a la postre, el acceso al estado de bienestar y satisfacción que puede asociarse al término felicidad. Según las últimas investigaciones, existen diez razones por las que se dispara la productividad cuando el trabajador goza o aprende a disfrutar con su tarea: (...). (p. 95)

Las empresas trabajan hoy el tema de la felicidad con el ánimo de aumentar su producción, de modo que, la ciencia de la felicidad haya cobrado relevancia y poder con las millonarias y múltiples, subvenciones, donaciones y financiaciones recibidas por Seligman -padre de la psicología positiva- a través de instituciones públicas y privadas, con lo que la psicología positiva lograba abrirse un terreno en el mercado, gracias a nuevos postulados ofrecidos por la industria de la felicidad (Cabanas y Illouz, 2019).

Multinacionales como Coca-Cola también invirtieron en psicología positiva con el fin de encontrar métodos más baratos y eficientes de incrementar la productividad, reducir el estrés en el trabajo y promover el compromiso de los empleados con la cultura de la empresa. (p. 18)

Ya no había porque avergonzarse de la relación entre la psicología y el mercado de los servicios, productos y bienes que prometían el acceso a la felicidad y a la realización personal. Los científicos de la felicidad se harían cargo de que todo aquello que se vendiera bajo la etiqueta "felicidad" pasara el exigente y riguroso filtro de la ciencia. (p. 22)

Lo que se observa con lo anterior es una muestra de la industria de la felicidad promovida por la psicología positiva, con lo cual las empresas han tomado partido para beneficiarse económicamente.

En el significado de felicidad en el contexto económico de carácter ontológico es importante para la felicidad el sustento de las familias y la dignidad que la persona obtiene al trabajar; no obstante, el aspecto mencionado sobre la desnaturalización del dinero requiere mayor detenimiento. En esto, Mill (2014) es enfático: 
¿Qué diremos, por ejemplo, del amor al dinero? No hay nada originariamente que haga al dinero más deseable que a cualquier montón de guijarros brillantes. Su valor radica únicamente en el de las cosas que con él se pueden adquirir: los deseos de otras cosas distintas al dinero y para las que este es un medio de gratificación. Sin embargo, el amor al dinero no es sólo una de las fuerzas más poderosas que mueven al hombre, sino que el dinero es, en muchos casos, deseado en y por sí mismo. El deseo a poseerlo es, a menudo, más fuerte que el deseo de utilizarlo, y continúa incrementando cuando se desvanecen todos los deseos que apuntan a fines que le trascienden y que son conseguidos por su mediación. Puede decirse, pues, en verdad, que el dinero no es deseado con vistas a un fin, sino que es parte de dicho fin. De construir un medio para la felicidad, se ha convertido a sí mismo en el principal constituyente de la concepción que un individuo se forma de la felicidad. (p. 118)

En cuanto al significado de felicidad de carácter empático-compasivo en el plano colectivo, dice Mill (2014) que:

Como medio para alcanzar más aproximadamente este ideal, la utilidad recomendará, en primer término, que las leyes y organizaciones sociales armonicen en lo posible la felicidad o (como en términos prácticos podría denominarse) los intereses de cada individuo con los intereses del conjunto. En segundo lugar, que la educación y la opinión pública, que tienen un poder tan grande en la formación humana, utilicen de tal modo ese poder que establezcan en la mente de todo individuo una asociación indisoluble entre su propia felicidad y el bien del conjunto. (p. 80)

Ricard (2016) complementa la anterior postura en la perspectiva de un bienestar y felicidad colectiva coadyuvando al significado de felicidad en el contexto social de carácter empático-compasivo desde el plano colectivo; en efecto:

Aunque no seamos iguales en el plano de la fuerza física, de las capacidades intelectuales, o de la riqueza en el momento de nacer, podemos decir que sí somos iguales en nuestro deseo de no sufrir y de realizarnos en la vida. La sociedad no puede pretender imponerles a todos una felicidad a medida. En cambio, tiene el deber de no abandonar a los que sufren. No podemos impedir que se den las desigualdades, sin embargo, tenemos que hacer todo lo posible para evitar que perduren. Una sociedad individualista hará 
pocos esfuerzos en este sentido, mientras que una sociedad que le da valor al altruismo y que coloca la suerte de los demás en el centro de sus preocupaciones velará por corregir las desigualdades, fuente de sufrimientos, de discriminaciones, de dificultades para realizarse en la vida y de acceso reducido a la educación y a la salud. (Ricard, 2016, p. 567)

Significado de felicidad en el contexto social de carácter político:

- Es la capacidad racional y práctica del ciudadano para afrontar las imposiciones relativas al consumo y la resolución de necesidades creadas a partir de la concienciación de aquellas que obedecen a la naturaleza de las dinámicas existenciales en el contexto aprehendido en tensión con las creadas por una sociedad de consumo.

En otras palabras:

El progreso hacia la libertad es un proceso dialéctico entre la lucha por la individuación en contra del deseo de volver a una unidad integrada, la autonomía frente a la aquiescencia, el crecimiento a pesar de la soledad frente a la sumisión a las autoridades irracionales, ya sean internas o exteriorizadas. Las tendencias a favor de la sumisión se manifiestan en no pocos aspectos de las reformas luteranas y calvinistas; también se manifiestan en las estructuras del capitalismo (...). (Xirau, 2013, pp. 38-39)

El concepto de libertad empleado por Xirau (2013) en la argumentación mencionada, puede ser análogo y complementario al concepto de concienciación del que se ocupa este trabajo. Y, en consecuencia, los ciudadanos de Manizales se ven inmersos en tales circunstancias.

\section{Conclusiones}

Los hallazgos de esta investigación permiten describir la comprensión de seis horizontes interpretativos a cerca de los significados de felicidad de los ciudadanos de Manizales para 2018. La discusión se realizó de acuerdo con los intereses de la investigación, haciendo énfasis en los horizontes relativos a la sociedad de consumo y otro horizonte relativo a la felicidad comprendida desde la interdependencia de los ciudadanos como característica principal para la estructuración de una sociedad realmente feliz. 
Se puede concluir la existencia de una constante disyuntiva de una sociedad que por tener una tradición e influencia del capitalismo adopta una perspectiva de felicidad en torno al paradigma del desarrollo económico y otra fundada en la naturaleza del ser humano consciente de una felicidad construida, a partir del vínculo empático-compasivo.

El asunto de la felicidad continúa perfilándose como alternativa a la crisis de las sociedades occidentales, en tanto que es necesario realizar investigaciones en torno al tema que le aporten al avance científico en materia de sostenibilidad social, humana y ambiental.

Para comprender los significados de felicidad en ciudadanos de Manizales fue trascendental el diálogo logrado en el grupo focal, las narrativas de los manizaleños permitieron aflorar una realidad oculta, interpretar y comprender significados de felicidad provenientes de la intersubjetividad, gracias también a la propuesta metodológica brindada por la filosofía hermenéutica; una herramienta acorde al requerimiento del trabajo cualitativo, así, la racionalidad práctica permite producir un conocimiento sin la necesidad de fórmulas tendientes a estandarizar o, a cuantificar realidades que revisten por sí mismas una forma especial de abordarlas o a la postre sustentar y complementar de algún modo una forma algorítmica.

En otro sentido, el tópico felicidad ha sido abordado por diferentes disciplinas, como la psicología positiva, la economía de la felicidad, la filosofía, teología, y los conocimientos ancestrales; todas con sus particularidades, bondades y cuestionamientos, teorías y métodos. Esta investigación no fue la excepción, tuvo su enfoque y sus resultados. Sin embargo, se puede observar que aportes de la economía de la felicidad como la paradoja de Easterlin, para el caso de los manizaleños participantes en el grupo focal, tiene un comportamiento similar al encontrado en la anterior investigación al revelar que la riqueza no necesariamente guarda relación directa con la felicidad.

Queda abierta la discusión sobre la dicotomía de una sociedad con una tradición solidaria por medio de un vínculo empático-compasivo y las influencias de un sistema político y económico capitalista capaz de romper dicho tejido social.

(SFRCP): significado de felicidad relativo al contexto político.

(SFRCEC): significado de felicidad relativo al contexto económico.

(SFRCS): significado de felicidad relativo al contexto social. 
(SFRCE): significado de felicidad relativo al contexto espiritual. (SFRCA): significado de felicidad relativo al contexto ambiental. (NPCA): narrativa participante contexto ambiental. (NPCP): narrativa participante contexto político. (NPCS): narrativa participante contexto social.

\section{Referencias}

Baquero, M, (2016). Narrativas de maestras acerca del cuidado de niños y niñas en el municipio de Caparrapí afectado por el conflicto armado colombiano (tesis doctoral no publicada). Universidad Distrital Francisco José de Caldas, Bogotá, Colombia.

Bentham, J. (2008). Los principios de la moral y la legislación. Buenos Aires, Argentina: Claridad S.A.

Cabanas, E. y Illouz, E. (2019). Happycracia: Cómo la ciencia y la industria de la felicidad controlan nuestras vidas. Barcelona: Editorial Planeta, S.A.

Enríquez, R. (2000). Redes sociales y pobreza: mitos y realidades. Revista de estudios de género la ventana. (40), 36-72. Recuperado de http://www.redalyc.org/ pdf/884/88412392004.pdf

Espinoza, L. (2015). Maestría en Felicidad. Claves y enseñanzas para recorrer el camino de la vida plena. Bogotá, Colombia: Intermedio Editores.

Gadamer, H. (2003). Verdad y método I. Salamanca, España: Ediciones Sígueme.

Herrera, J. (2010). La comprensión de lo social. Horizonte hermenéutico de lo social. Bogotá, Colombia: Ediciones Antropos Ltda.

Jufresa, M., Camps, M. y Mestre, F. (1994). Obras. Barcelona, España: Ediciones Altaya.

Lofti, E. (2012). La entrega. En J. Fernández, S. Ibarra y J.R. Lucas (Eds.). Hablemos de Felicidad (pp. 113-120). Barcelona, España: Urano, S.A.

Londoño, O.L. (1936) Manizales. Manizales, Colombia: Banco de la República Biblioteca Luis Ángel Arango.

Lyubomirsky, S. (2012). La ciencia de la felicidad. En J. Fernández, S. Ibarra y J. R. Lucas (Eds.). Hablemos de Felicidad (pp.105-112). Barcelona, España: Urano, S.A.

Margot, J. (2007). La felicidad. Praxis Filosófica, (25), 55-79. Recuperado de https://www. redalyc.org/pdf/2090/209014642004.pdf

Mill, J. (2014). El utilitarismo. Madrid, Alianza Editorial, S.A.

Pinzón, L. (2017). Factores asociados a la pobreza subjetiva en Colombia: un estudio desde el enfoque de las capacidades y la economía de la felicidad. Desarrollo y sociedad, (13). Recuperado de http://www.scielo.org.co/pdf/dys/n78/n78a02.pdf

Ricard, M. (2016). En defensa del altruismo. París: Nil éditions.

Rojas, M. (2009). Economía de la felicidad: hallazgos relevantes respecto al ingreso y el bienestar. El trimestre económico (551), 537-573. Recuperado de http://www.eltrimestreeconomico.com.mx/index.php/te/article/view/489/527 
Tula, F. (2015). Felicidad: lecciones de una nueva ciencia. Sociologías, 17(40), 416-425. Recuperado de http://www.scielo.br/scielo.php?script=sci_arttext\&pid=S151745222015000300416\&lng=es\&tlng=es

Vallejo, A. (2012). Trabajo y Felicidad. En J. Fernández, S. Ibarra y J. R. Lucas (Eds.). Hablemos de Felicidad (pp. 92-98). Barcelona, España: Urano, S.A.

Vergara, F. (2008). Gadamer y la "comprensión efectual": Diálogo y tradición en el horizonte de la Koiné Contemporánea. Universum (Talca), 23(2), 184-200. Recuperado de https://dx.doi.org/10.4067/S0718-23762008000200011

Xirau, R. (2013). Erich Fromm y la naturaleza humana. Ciudad de México. 